\title{
Capacidade de restabelecimento da grama-estrela-africana após aplicação de glifosato em pré-semeadura de milho
}

\author{
Alexandre Magno Brighenti(1), Carlos Eugênio Martins ${ }^{(1)}$, Fausto Souza Sobrinho(1), \\ Wadson Sebastião Duarte da Rocha ${ }^{(1)}$, Leonardo Henrique Ferreira Calsavara ${ }^{(2)}$ e Lucas de Cássio Nicodemos ${ }^{(3)}$ \\ (1)Embrapa Gado de Leite, Rua Eugênio do Nascimento, oo 610, Bairro Dom Bosco, CEP $36038-330$ Juiz de Fora, MG. \\ E-mail: brighent@cnpgl.embrapa.br, caeuma@cnpgl.embrapa.br, fausto@cnpgl.embrapa.br, wadson@cnpgl.embrapa.br(2)Emater, Rua \\ Major Mendonça, no 103, Centro, CEP 36330-000 Coronel Xavier Chaves, MG. E-mail: leonardo.calsavara@emater.mg.gov.br ${ }^{(3)}$ Centro de \\ Ensino Superior de Juiz de Fora, Rua Luz Interior, s/nº, CEP 36030-776 Juiz de Fora, MG. E-mail: lucasnicodemos@yahoo.com.br
}

Resumo - O objetivo deste trabalho foi avaliar a capacidade de restabelecimento de pastagem de grama-estrela-africana (Cynodon nlemfuensis) após aplicação do herbicida glifosato, na pré-semeadura da cultura do milho. Utilizou-se o delineamento experimental de blocos ao acaso, com quatro repetições. Os tratamentos foram: doses do equivalente ácido (e.a.) do herbicida glifosato $\left(0,720,1.440,2.160,2.880\right.$ e $\left.3.600 \mathrm{~g} \mathrm{ha}^{-1}\right)$ e a testemunha capinada. A grama-estrela-africana é tolerante às doses normalmente recomendadas do herbicida (720 a $1.080 \mathrm{~g} \mathrm{ha}^{-1}$ de e.a). Doses de glifosato de 1.232 a $1.439 \mathrm{~g} \mathrm{ha}^{-1}$ de e.a. suprimem a grama-estrela-africana, evitam sua competição com a cultura do milho, e permitem a recuperação da pastagem após a colheita do milho.

Termos para indexação: Cynodon nlemfuensis, consórcio, formação de palhada, integração lavoura-pecuária, plantio direto, tolerância ao glifosato.

\section{Recovery capacity of African star grass after application of glyphosate in pre-sowing of corn}

\begin{abstract}
The objective of this work was to evaluate the recovery capacity of African star grass (Cynodon nlemfuensis) after glyphosate application in pre-sowing of corn. A randomized block design was used, with four replicates. The treatments were doses of acid equivalent (a.e.) of the herbicide glyphosate $(0,720,1,440,2,160$, 2,880 , and 3,600 $\mathrm{g} \mathrm{ha}^{-1}$ ) and a hoed control. African star grass is tolerant to the usually recommended doses of the herbicide (720 to $1,080 \mathrm{~g} \mathrm{ha}^{-1}$ a.e.). Doses of glyphosate, ranging from 1,232 to $1,439 \mathrm{~g} \mathrm{ha}^{-1}$ a.e. suppress the grass, avoid its competition with corn, and allow the recovery of the pasture after the corn harvest.
\end{abstract}

Index terms: Cynodon nlemfuensis, intercropping, straw formation, forage grasses, crop-livestock integration, no tillage, glyphosate tolerance.

\section{Introdução}

Sistemas extensivos de uso de pastagens em criações de animais continuam sendo a forma mais difundida no Brasil. O modelo de utilização de pastagens, em solos com aptidão agrícola desfavorável, justifica, pelo menos em parte, os baixos índices zootécnicos e as baixas produtividades observadas.

Nesse contexto, sistemas como os de integração lavoura-pecuária-floresta (ILPF) são bem aceitos em razão dos inúmeros benefícios que podem proporcionar, principalmente no que tange à qualidade química, física e biológica dos solos. Entretanto, a maioria das pesquisas com culturas forrageiras em sistemas de ILPF avalia espécies do gênero Urochloa, e são poucos os estudos sobre outras espécies como, por exemplo, as do gênero Cynodon, potencialmente adequadas a sistemas em consórcio.
Os capins do gênero Cynodon, como a grama-estrela-africana (Cynodon nlemfuensis Vanderyst), têm sido redescobertos como alternativas para alimentação de rebanhos e formação de novas pastagens (Pedreira, 2005). Essa espécie caracteriza-se por ser perene, com estolões longos e prostrados sobre o solo. Suas folhas apresentam limbo largo e hastes grossas, sem rizoma (Athayde et al., 2005). Algumas cultivares foram lançadas nos Estados Unidos, resultantes do melhoramento genético (Seghese, 2009). Entre as mais promissoras, destacam-se a 'Florona'e a 'Florico', pela elevada produção de forragem de qualidade e pela resistência a pragas, doenças e baixas temperaturas (Mislevy et al., 1989a, 1989b).

De acordo com Favoreto et al. (2008), C. nlemfuensis em condição de pastejo rotacionado, com intervalo de 30 dias, mais suplemento de $2 \mathrm{~kg}$ por vaca por dia de concentrado, atende à demanda energética nutricional

Pesq. agropec. bras., Brasília, v.47, n.10, p.1443-1448, out. 2012 
de mantença e produção de $11,7 \mathrm{~kg}$ de leite por vaca por dia. Evangelista et al. (2000) informam que a grama-estrela-africana, ensilada logo após o corte ou submetida a até 3 horas de emurchecimento, pode ser armazenada, satisfatoriamente, na forma de silagem.

Embora a grama-estrela-africana seja considerada excelente forrageira e uma alternativa para sistemas ILPF, há necessidade de desenvolver tecnologias de manejo dessa espécie com o uso de herbicidas, para favorecer a implantação dos cultivos em consórcio.

O objetivo deste trabalho foi avaliar a capacidade de restabelecimento de pastagem de grama-estrelaafricana (Cynodon nlemfuensis) após aplicação do herbicida glifosato, na pré-semeadura da cultura do milho.

\section{Material e Métodos}

Dois experimentos foram implantados na Embrapa Gado de Leite, Coronel Pacheco, MG (2132'17"S; $\left.43^{\circ} 14 ' 30^{\prime \prime W}\right)$. O clima da região, segundo a classificação de Köppen, é do tipo Cwa, mesotérmico, definido como subtropical, chuvoso no verão e seco no inverno. A pluviosidade média anual é de aproximadamente $1.500 \mathrm{~mm}$.

Utilizou-se o delineamento experimental de blocos ao acaso, com quatro repetições. Os tratamentos, em doses do equivalente ácido (e.a.) do herbicida glifosato, foram: $0,720,1.440,2.160,2.880$ e $3.600 \mathrm{~g} \mathrm{ha}^{-1}$ de e.a, além de testemunha capinada.

Quatro meses antes da implantação dos experimentos, o solo da área experimental foi arado e gradeado. Os estolões da grama-estrela-africana foram espalhados sobre a superfície do solo e incorporados com grade niveladora. Aguardou-se a formação e o completo fechamento da pastagem.

Em ambos os experimentos, as aplicações dos tratamentos foram realizadas 15 dias antes da semeadura da cultura do milho, com uso de pulverizador experimental (Herbicat Ltda., Catanduva, SP), mantido à pressão constante, equivalente a $2 \mathrm{kgf} \mathrm{cm}^{-2}$. A barra de pulverização tinha $1,5 \mathrm{~m}$ de largura útil, com quatro bicos de jato plano 110 015, distanciados em 0,5 m, e volume de pulverização equivalente a $150 \mathrm{~L} \mathrm{ha}^{-1}$. Por ocasião da aplicação do herbicida, as plantas de grama-estrela-africana apresentavam altura média de $0,6 \mathrm{~m}$.
Os experimentos 1 e 2 foram implantados em 20/5/2008 e em 10/5/2009, respectivamente. Utilizaram-se os híbridos de milho PZ-677 (Ouro Fino) e AG 1051 (Monsanto), respectivamente. A área das parcelas foi de $30 \mathrm{~m}^{2}(5 \times 6 \mathrm{~m})$, com cinco linhas de milho. Os experimentos foram irrigados semanalmente, por aspersão, com $15 \mathrm{~mm}$ de lâmina de água.

Para o plantio do milho, foi utilizada a semeadora de plantio direto SAM 200 (Semeato Ltda., Passo Fundo, RS), com três linhas de plantio. O espaçamento entrelinhas foi de $0,87 \mathrm{~m}$, com estande de, aproximadamente, 57.000 plantas por hectare. A adubação de semeadura foi de 444 e $370 \mathrm{~kg} \mathrm{ha}^{-1}$ do fertilizante N-P-K (8-28-16 mais $0,5 \%$ de zinco), para os experimentos 1 e 2 , respectivamente. As adubações de cobertura foram parceladas em duas etapas, aos $25 \mathrm{e}$ aos 35 dias após a emergência do milho, com o emprego de $300 \mathrm{~kg} \mathrm{ha}^{-1}$ do fertilizante N-P-K (20-05-20).

$\mathrm{O}$ efeito do herbicida sobre as plantas da forrageira foi avaliado visualmente, aos 10, 20 e 30 dias após a aplicação dos tratamentos (DAA), com uso de escala percentual de controle de 0 a 100\% (Gazziero et al., 1995). Em ambos os experimentos, foram medidas as alturas de dez plantas de milho por parcela, com uso de régua graduada, na pré-colheita da cultura do milho. Foram colhidas as plantas de milho das três linhas centrais de cada parcela, para determinação da produtividade de matéria fresca, na época recomendada para ensilagem (experimento 1), e a produtividade de grãos (experimento 2).

Trinta dias após a colheita do milho, avaliou-se a recuperação da pastagem, em ambos os experimentos. As plantas foram cortadas rente ao solo, em área de $1 \mathrm{~m}^{2}$, e pesadas em seguida.

As análises estatísticas foram realizadas com uso do programa Saeg (Ribeiro Junior, 2001). Os resultados obtidos para altura de plantas de milho, produtividade de matéria fresca de plantas e produtividade de grãos do milho foram submetidos à análise de variância, tendo-se ajustado essas variáveis a equações não lineares (modelo "broken stick") (Colweel et al., 1988; Spadotto et al., 1994; Brighenti et al., 2004), de acordo com a dose empregada do herbicida. Utilizou-se a equação $\mathrm{y}=\mathrm{A}+\{\mathrm{B}[(\mathrm{x}-\mathrm{P})-(|\mathrm{x}-\mathrm{P}|)]\}$, em que: $\mathrm{A}$ é a altura ou a produtividade máxima; $\mathrm{B}$ é a metade do ângulo entre a projeção do patamar máximo e a reta inclinada; e P é o valor de x quando a curva muda seu comportamento. 
Além disso, foram ajustados modelos de regressão do tipo raiz quadrada $\left[\mathrm{y}=\mathrm{A}-\mathrm{B}(\mathrm{x})^{0,5}+\mathrm{Cx}\right]$, tendo-se utilizado, como variável resposta, a produtividade de matéria fresca da grama-estrela-africana 30 dias após a colheita do milho.

\section{Resultados e Discussão}

As médias mensais de temperatura do ar e de pluviosidade, no período experimental, encontram-se na Tabela 1.

O controle da grama-estrela-africana à dosagem de $720 \mathrm{~g} \mathrm{ha}^{-1}$ de e.a foi baixo, nas primeiras avaliações e aos 30 DAA, com valores de 45 e $53 \%$, nos experimentos 1 e 2, respectivamente (Tabela 2). As folhas apresentaram leve clorose, com posterior recuperação das plantas. A clorose ocorreu porque o glifosato inibe a síntese dos aminoácidos aromáticos fenilalanina, tirosina e triptofano, o que provoca o amarelecimento progressivo das folhas, murcha e morte das plantas (Rodrigues \& Almeida, 2005).

A dose de $1.440 \mathrm{~g}$ e.a. ha ${ }^{-1}$ produziu efeito mais pronunciado, com percentual de controle de $68-70 \%$, na última avaliação. Contudo, esses valores ainda podem ser considerados baixos, já que não resultaram na morte da forrageira. A supressão das espécies forrageiras com doses menores de herbicidas é considerada vantajosa em sistemas de integração lavoura-pecuária, pois evita a interferência destas com as culturas e permite a rebrota de estruturas vegetativas da pastagem, após a colheita dos cultivos.

Santos et al. $(2006,2008)$ observaram alta tolerância de Tifton 85 (Cynodon spp.) ao glifosato. A dose de $720 \mathrm{~g} \mathrm{ha}^{-1}$ de e.a resultou em baixa intensidade de sintomas, caracterizados por leve clorose das folhas, brotações de gemas laterais e redução de crescimento. Santos et al. (2007) também relataram alta capacidade de rebrota de Tifton 85 submetido à dose de $1.800 \mathrm{~g} \mathrm{ha}^{-1}$ de e.a. Os autores somente observaram controle superior a $90 \%$ quando as doses foram acima de $2.637 \mathrm{e}$ $3.607 \mathrm{~g} \mathrm{ha}^{-1}$ de e.a, em aplicações realizadas no inverno e no verão, respectivamente (Santos et al., 2010).

Tabela 1. Médias mensais de temperatura do ar e pluviosidade durante a condução dos experimentos.

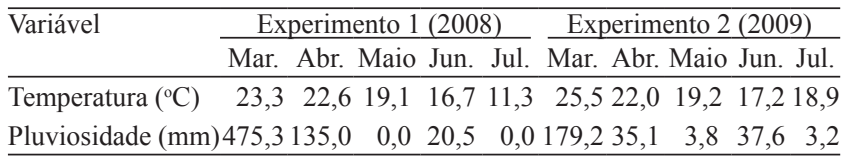

Acredita-se que a tolerância ao glifosato possa estar relacionada a grandes quantidades de reservas de amido situadas nas estruturas vegetativas da planta, que atuariam como barreiras à translocação do herbicida (Machado, 2005; Santos et al., 2007). Tuffi Santos et al. (2004), ao avaliar Commelina diffusa Burm. f. e Commelina benghalensis L., observaram que a tolerância ao glifosato era maior em $C$. diffusa do que em C. benghalensis, em decorrência da maior quantidade de amido encontrada no caule da primeira espécie. A grande quantidade de estruturas vegetativas por onde o herbicida tem de se distribuir, após ser absorvido pelas folhas, também é uma das razões da necessidade de maiores dosagens para obtenção de resultados eficazes no controle de espécies do gênero Cynodon (Martini et al., 2002).

Com o uso das três maiores doses, observou-se clorose inicial das folhas, seguida de necrose, com percentuais altos de controle, que variaram de 80 a $100 \%$, aos 30 DAA, em ambos os experimentos. A maior dose utilizada (3.600 $\mathrm{g} \mathrm{ha}^{-1}$ de e.a.) causou morte total das plantas, na última avaliação do controle (Tabela 2). Abdullahi (2002) verificou que, para proporcionar controle satisfatório da grama-bermuda [Cynodon dactylon (L.) Pers.], foi necessária uma aração acompanhada da aplicação de glifosato a $2.160 \mathrm{~g} \mathrm{ha}^{-1}$ de e.a., após a rebrota da espécie.

As doses de $1.439,9$ e $1.327,1 \mathrm{~g} \mathrm{ha}^{-1}$ de e.a. não interferiram no crescimento do milho, que alcançou altura de 1,9 a 2,1 $\mathrm{m}$, nos experimentos 1 e 2, respectivamente (Figura 1). Quanto à produtividade de matéria fresca, observou-se que a dose $1.232,9 \mathrm{~g} \mathrm{ha}^{-1}$ proporcionou 45,36 $\mathrm{Mg} \mathrm{ha}^{-1}$ (Figura $2 \mathrm{~A}$ ). Em relação à produtividade de grãos de milho, a dose de $1.260,4 \mathrm{~g}$ ha $^{-1}$ resultou em 7,17 Mg ha ${ }^{-1}$ (Figura $2 \mathrm{~B}$ ).

Tabela 2. Percentagem de controle de plantas de grama-estrela-africana aos 10,20 e 30 dias após a aplicação das doses do herbicida glifosato em pré-semeadura da cultura do milho, nos experimentos 1 e 2 .

\begin{tabular}{lccccccc}
\hline Dose de glifosato & \multicolumn{3}{c}{ Experimento 1} & & \multicolumn{3}{c}{ Experimento 2 } \\
\cline { 2 - 4 } \cline { 7 - 8 }$\left(\mathrm{g} \mathrm{ha}^{-1}\right.$ de e.a. $)$ & 10 dias & 20 dias & 30 dias & & 10 dias & 20 dias & 30 dias \\
\hline Test. capinada & 100 & 100 & 100 & & 100 & 100 & 100 \\
720 & 15 & 25 & 45 & & 19 & 29 & 53 \\
1.440 & 22 & 55 & 68 & & 20 & 57 & 70 \\
2.160 & 30 & 75 & 81 & & 31 & 78 & 80 \\
2.880 & 45 & 80 & 91 & & 46 & 81 & 93 \\
3.600 & 51 & 88 & 100 & & 54 & 89 & 100 \\
\hline
\end{tabular}

e.a., equivalente ácido. Test., testemunha. 
Após a colheita do milho, a pastagem recuperou-se, principalmente nas duas menores doses de glifosato. No experimento 1 , a dose de 1.232,93 $\mathrm{g} \mathrm{ha}^{-1}$ de e.a. proporcionou $15,05 \mathrm{Mg} \mathrm{ha}^{-1}$ de matéria fresca de grama-estrela-africana, 30 dias após a colheita do milho (Figura 3). Já no experimento 2, a dose de $1.260,4 \mathrm{~g} \mathrm{ha}^{-1}$ de e.a. resultou em 11,24 Mg ha ${ }^{-1}$.

Doses intermediárias do herbicida (1.232 a 1.439 $\mathrm{g} \mathrm{ha}^{-1}$ de e.a.) causaram a supressão da forrageira, o que permitiu o estabelecimento das lavouras de milho. Além disso, as plantas remanescentes da forrageira, após a colheita do milho, permitiram o restabelecimento da pastagem.

Doses acima de $1.232 \mathrm{~g} \mathrm{ha}^{-1}$ de e.a. proporcionaram valores de altura e produtividade de matéria fresca e grãos de milho superiores aos obtidos na testemunha capinada. Isso porque não foi possível eliminar todas as plantas de grama-estrela-africana presentes na linha da cultura do milho, no tratamento com a capina, para que não se pusesse em risco o estande.

As aplicações de doses maiores que $2.160 \mathrm{~g} \mathrm{ha}^{-1}$ dee.a., embora nãotenham erradicadoa grama-estrela-africana, reduziram a cobertura vegetal da área, o que permitiu o surgimento de plantas daninhas no restabelecimento

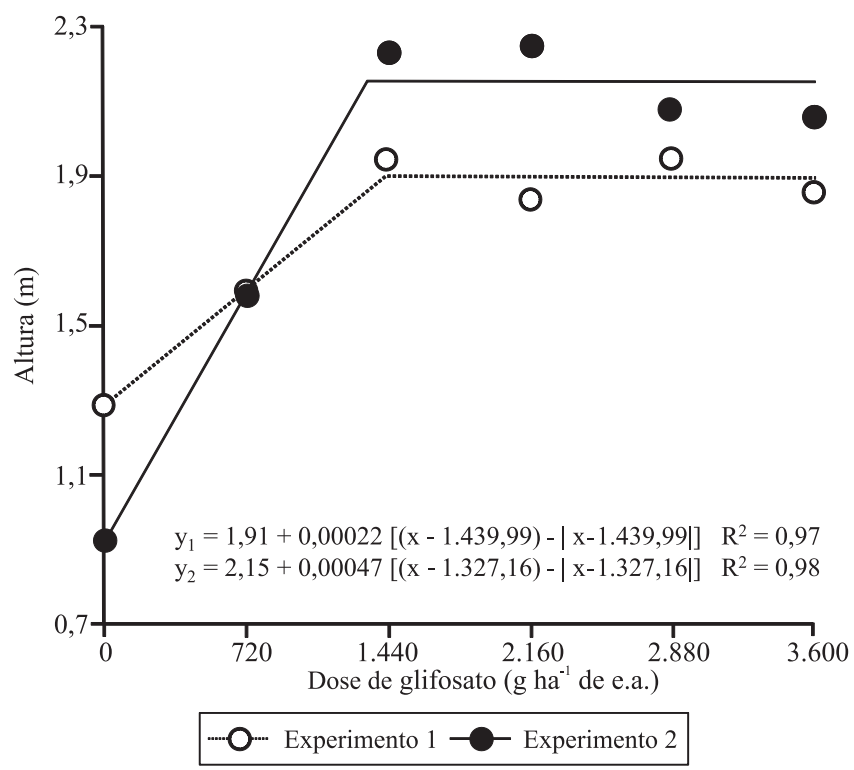

Figura 1. Altura de plantas de milho (m), em função da aplicação das doses do herbicida glifosato, em présemeadura da cultura, nos experimentos 1 e 2 . Testemunha capinada $=1,61 \mathrm{~m}$, para o experimento 1 , e $1,76 \mathrm{~m}$ para o experimento 2 . da pastagem. Além disso, há a possibilidade de que cultivos sucessivos de milho, com doses mais altas de glifosato em pré-semeadura, reduzam acentuadamente a densidade da forrageira, o que levaria à necessidade de replantio. Como a grama-estrela-africana é comumente propagada por via vegetativa, seu plantio é trabalhoso e requer revolvimento do solo, o que contraria os preceitos de manejo e conservação de solo no plantio direto.
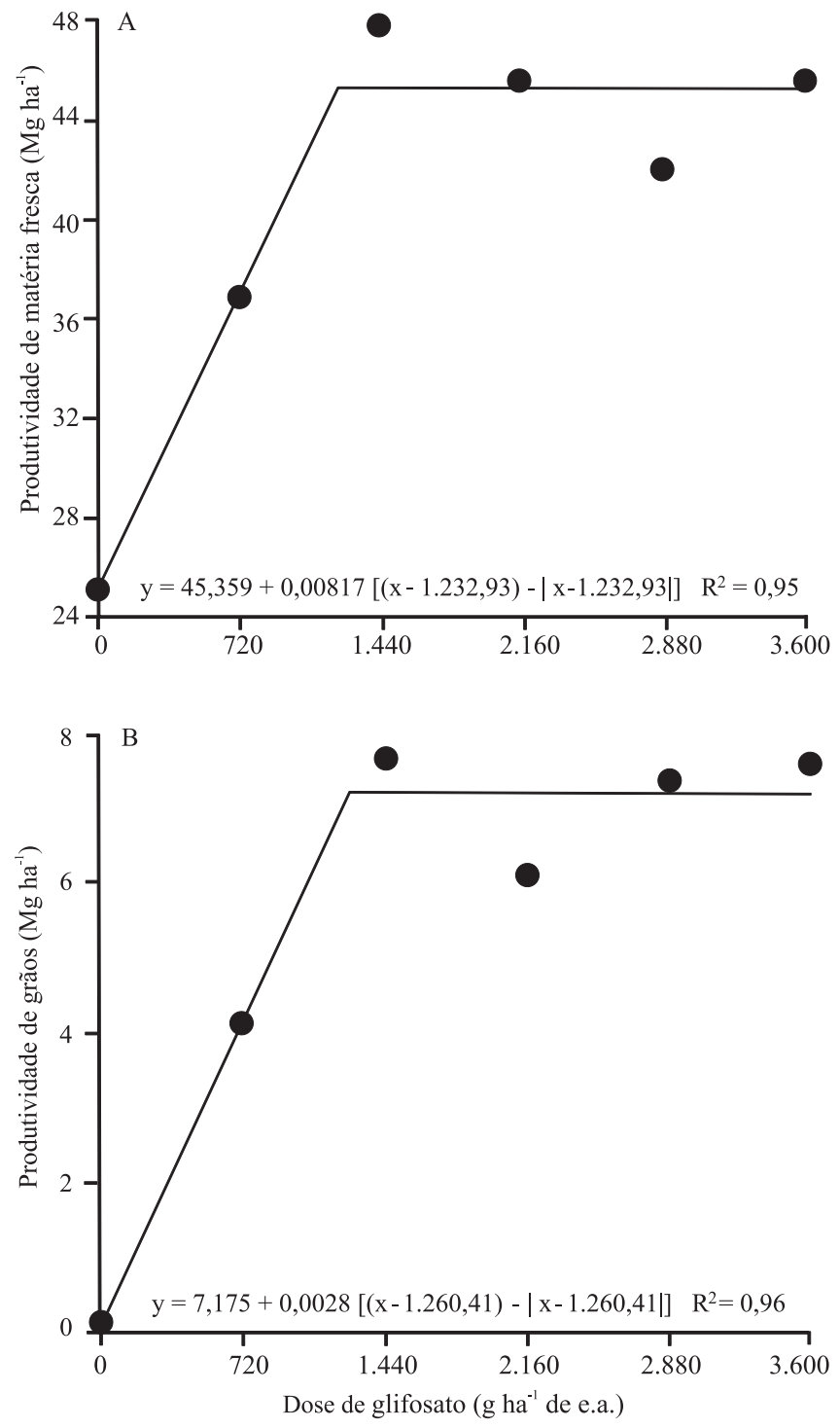

Figura 2. Produtividade de matéria fresca de plantas de milho no experimento 1 (A) e produtividade de grãos no experimento 2 (B), em função das doses de glifosato, em pré-semeadura da cultura. Testemunha capinada 39,7 e 3,77 $\mathrm{Mg} \mathrm{ha}^{-1}$ no experimento 1 e 2 , respectivamente. 


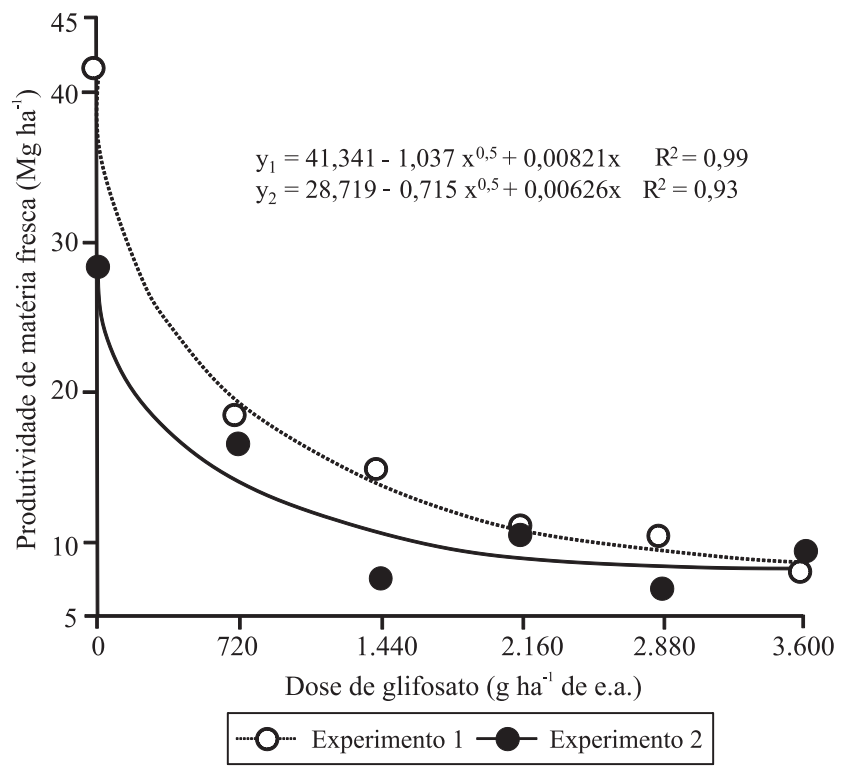

Figura 3. Produtividade de matéria fresca de plantas de grama-estrela-africana, aos 30 dias após a colheita do milho, em função da aplicação de doses do herbicida glifosato, em pré-semeadura da cultura, nos experimentos 1 e 2 . Testemunha capinada: $15,29 \mathrm{Mg} \mathrm{ha}^{-1}$, para o experimento 1 , e 9,82 $\mathrm{Mg} \mathrm{ha}^{-1}$ para o experimento 2 .

\section{Conclusões}

1. A utilização do glifosato aplicado sobre a grama-estrela-africana, em pré-semeadura da cultura do milho, torna viável o plantio direto do milho sobre a pastagem.

2. A grama-estrela-africana é tolerante às doses normalmente recomendadas do herbicida glifosato (720 a $1.080 \mathrm{~g} \mathrm{ha}^{-1}$ de e.a.).

3. Doses de glifosato de 1.232 a $1.439 \mathrm{~g} \mathrm{ha}^{-1} \mathrm{de}$ e.a. suprimem a grama-estrela-africana, evitam sua competição com a cultura do milho e permitem a recuperação da pastagem após a colheita do milho.

\section{Agradecimentos}

À Fundação deAmparoà Pesquisa do Estado de Minas Gerais e ao Conselho Nacional de Desenvolvimento Científico e Tecnológico, pelo apoio financeiro.

\section{Referências}

ABDULLAHI, A.E. Cynodon dactylon control with tillage and glyphosate. Crop Protection, v.21, p.1093-1100, 2002.
ATHAYDE, A.A.R.; CARVALHO, R. de C.R.; MEDEIROS, L.T.; VALERIANO, A.R.; ROCHA, G.P. da. Gramíneas do gênero Cynodon - cultivares recentes no Brasil. Lavras: Universidade Federal de Lavras, 2005. p.1-14. (Boletim técnico, 73).

BRIGHENTI, A.M.; CASTRO, C.; OLIVEIRA JUNIOR, R.S.; SCAPIM, C.A.; VOLL, E.; GAZZIERO, D.L.P. Períodos de interferência de plantas daninhas na cultura do girassol. Planta Daninha, v.22, p.251-257, 2004.

COLWEEL, J.D.; SUHET, A.R.; RAIJ, B. van. Statistical procedures for developing general soil fertility models for variable regions. Australia: CSIRO, 1988. 68p. (CSIRO. Division of Soils. Divisional Report, 93).

EVANGELISTA, A.R.; LIMA, J.A. de; BERNARDES, T.F. Avaliação de algumas características da silagem de gramínea estrela-roxa (Cynodon nlemfuensis Vanderyst). Revista Brasileira de Zootecnia, v.29, p.941-946, 2000.

FAVORETO, M.G.; DERESZ, F.; FERNANDES, A.M.; VIEIRA, R.A.M.; FONTES, C.A.A. Avaliação nutricional da grama-estrela cv. Africana para vacas leiteiras em condições de pastejo. Revista Brasileira de Zootecnia, v.37, p.319-327, 2008.

GAZZIERO, D.L.P.; VELINI, E.D.; OSIPE, R. Procedimentos para instalação, avaliação e análise de experimentos com herbicidas. Londrina: Sociedade Brasileira da Ciência das Plantas Daninhas, 1995. 42p.

MACHADO, A.F. Biologia e controle químico de Digitaria insularis (L.). 2005. 45p. Dissertação (Mestrado) - Universidade Federal de Viçosa, Viçosa.

MARTINI, G.; PEDRINHO JUNIOR, A.F.F.; FELICI, G.V.; PIVA, F.M.; DURIGAN, J.C. Eficácia de uma nova formulação de glifosato para o controle de grama-seda (Cynodon dactylon), em pomar de citros. Revista Brasileira de Fruticultura, v.24, p.683-686, 2002.

MISLEVY, P.; BROWN, W.F.; CARO-COSTAS, R.; VICENTE-CHANDLER, J.; DUNAVIN, L.S.; HALL, D.W.; KALMBACHER, R.S.; OVERMAN, A.J.; RUELKE, O.C.; SONODA, R.M.; SOTOMAYOR-RIOS, A.; STANLEY JUNIOR, R.L.; WILLIAMS, N.J. Florico stargrass. Florida: University of Florida, 1989a. 15p. (Circular, 361).

MISLEVY, P.; BROWN, W.F.; DUNAVIN, L.S.; HALL, D.W.; KALMBACHER, R.S.; OVERMAN, A.J.; RUELKE, O.C.; SONODA, R.M.; STANLEY JUNIOR, R.L.; WILLIAMS, M.J. Florona stargrass. Florida: University of Florida, 1989b. 13p. (University of Florida. Circular, 362).

PEDREIRA, C.G.S. Capins do gênero Cynodon: histórico e potencial para a produção brasileira. In: VILELA, D.; RESENDE, J.C. de; LIMA, J. (Ed.). Cynodon: forrageiras que estão revolucionando a pecuária brasileira. Juiz de Fora, 2005. p.33-58.

RIBEIRO JUNIOR, J.I. Análises estatísticas no SAEG. Viçosa: Universidade Federal de Viçosa, 2001. 301p.

RODRIGUES, B.N.; ALMEIDA, F.S. de. Guia de herbicidas. 5.ed. Londrina, 2005. 592p.

SANTOS, M.V.; FERREIRA, F.A.; FREITAS, F.C.L.; IKEDA, A.K.; OLIVEIRA, F.L.R.; ROCHA, D.C.C.; LIMA, J.G.; SILVA, F.N.A.; ASSIS, F.G.V. Tolerância do Tifton 85 (Cynodon spp.) e 
da Brachiaria brizantha ao glyphosate. Planta Daninha, v.26, p.353-360, 2008.

SANTOS, M.V.; FERREIRA, F.A.; FREITAS, F.C.L.; TUFFI SANTOS, L.D.; FONSECA, D.M. Controle da Brachiaria brizantha com o uso do glyphosate após o estabelecimento do Tifton 85 (Cynodon spp.). Planta Daninha, v.24, p.813-819, 2006.

SANTOS, M.V.; FERREIRA, F.A.; FREITAS, F.C.L.; TUFFI SANTOS, L.D.; VIANA, J.M.; ROCHA, D.C.C.; FIALHO, C.M.T. Controle da Brachiaria brizantha, com o uso do glyphosate, na formação de pastagem de Tifton 85 (Cynodon spp.). Planta Daninha, v.25, p.149-155, 2007.

SANTOS, M.V.;FREITAS, F.C.L.;FERREIRA, F.A.; CARVALHO, A.J.; BRAZ, T.J.F.; CAVALI, J.; RODRIGUES, O.L. Tolerância do
Tifton 85 ao glyphosate em diferentes épocas de aplicação. Planta Daninha, v.28, p.131-137, 2010.

SEGHESE, M.A. Informações sobre gramíneas do gênero Cynodon. Maringá: CESUMAR, 2009. 15p. (Comunicado técnico, 1).

SPADOTTO, C.A.; MARCONDES, D.A.S.; LUIZ, A.J.B.; SILVAS, C.A.R. das. Determinação do período crítico para prevenção da interferência de plantas daninhas na cultura da soja: uso do modelo "broken-stick". Planta daninha, v.12, p.59-62, 1994.

TUFFI SANTOS, L.D.; MEIRA, R.M.S.A.; SANTOS, I.C.; FERREIRA, F.A. Efeito do glyphosate sobre a morfoanatomia das folhas e do caule de Commelina diffusa e C. benghalensis. Planta Daninha, v.22, p.101-108, 2004.

Recebido em 24 de fevereiro de 2012 e aprovado em 27 de setembro de 2012 